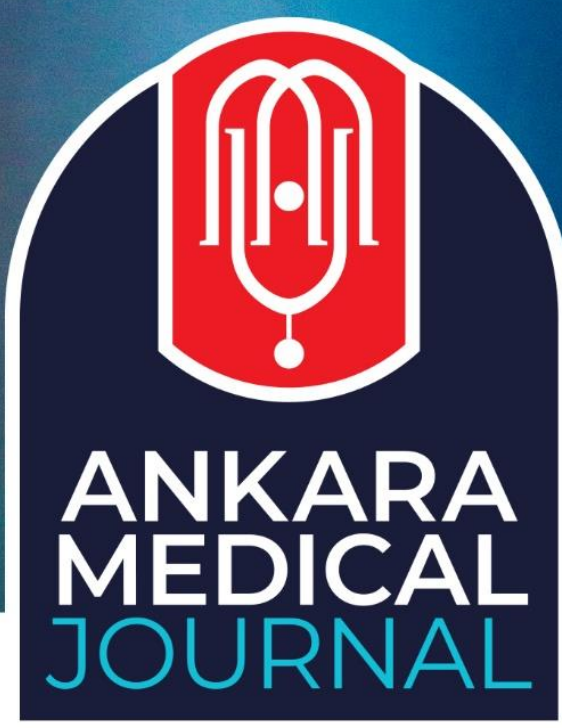

Editöre Mektup

Ankara Med J, 2021;(1):217-219 // 10 10.5505/amj.2021.48379

HAYAT EVE SIĞAR UYGULAMASI YOĞUNLUK HARITTASINDAN İSTANBUL'UN İLÇELERİ VE BÖLGELERININN COVID-19 RISSKININ SKORLANMASI

\title{
SCORING THE COVID-19 RISK OF DISTRICTS AND REGIONS OF ISTANBUL FROM THE DENSITY MAP OF HAYAT EVE SIGAR APPLICATION
}

(D) Bekir Aktura1', (D) Kursad Koc ${ }^{2}$, (D) Mustafa Andaç Derinpınar ${ }^{3}$ (i) Nilüfer Aktura4

${ }^{1}$ İstanbul Üniversitesi, Sağlık Bilimleri Enstitüsü Halk Sağlığı AD, İstanbul 2Bağımsız Araștırmacı, Ankara ${ }^{3}$ Reidin - Data Analytics, İstanbul

4İstanbul Medipol Üniversitesi, Tıp Fakültesi Aile Hekimliği AD, İstanbul

Yazışma Adresi / Correspondence:

Dr. Bekir Aktura (e-posta: bekiraktura@gmail.com)

Geliş Tarihi: 24.02.2021// Kabul Tarihi: 10.03.2021

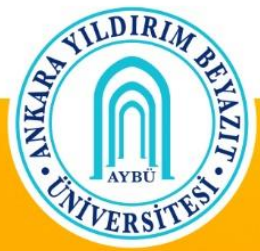

Ankara Yıldırım Beyazıt University Faculty of Medicine Department of Family Medicine 


\section{Sayın Editör,}

2019 aralık ayında Çin'de başlayıp tüm dünyaya yayılan Covid-19 salgını etkisini hala devam ettirmektedir. Ülkemizde 20 Şubat 2021 itibari ile 2,5 milyondan fazla, dünyada ise 110 milyondan fazla vaka görülmüştür. ${ }^{1}$

Covid-19 salgınından yaşlı ve kronik hastalığı olanların daha fazla etkilendiği bilinmektedir. Bununla birlikte Covid-19 salgınının etkisini artıran sosyal belirleyiciler üzerine de dünyada çalışılmaktadır. Yapılan çalışmalarda bölgesel olarak yüksek nüfus yoğunluğu, gelir düzeyinin düşüklügü, şehirde yaşayanların oranının yüksekliği gibi sosyal faktörlerin de Covid-19'dan etkilenme riskini arttığı gösterilmiştir.2,3

Bilindiği üzere ülkemizde bölgesel olarak lokasyon bazlı Covid-19 hastalık yoğunluğu Hayat Eve Sığar uygulamasından (HES) takip edilmektedir. Sağlık Bakanlığı iOS ve Android işletim sistemi olan telefon ve tabletlerde kullanılmak üzere Nisan 2020 tarihinde HES'i yayınlamıştır. HES ile, kişiler yaşadıkları bölgede ya da gitmek istedikleri yerdeki risk durumunu ve hastalık yoğunluğunu harita üzerinden görebilmektedirler. HES'de hastalık yoğunluğu Resim 1'deki gibi raporlanmaktadır. Uygulamadaki yoğunluk haritasından belli bir yakınlaşma seviyesine kadar harita büyütülmekte ve izin verilen en fazla yakınlaşma seviyesinde bölgelerin hastalık yoğunluğu Resim 1'deki gibi izlenebilmektedir. HES'de yoğunluk haritasının noktasal veri içermediği bölgesel yoğunluğu gösterdiği belirtilmektedir. Veriler sadece harita üzerinden raporlanmaktadır. Harita üzerinde renklendirmiş alanlar hastalık yoğunluğunu göstermektedir. Kırmızı alanın fazlalığı riskin yüksekliğini göstermektedir. HES deki yoğunluk haritasının önceki tarihlerdeki durumunu görmek mümkün değildir.

Modelimizde bölgesel Covid-19 riskinin skorlanması, HES bölgesel yoğunluk haritası verilerinin görüntü işleme yöntemi ile analiz edilmesi sonucunda yapılmaktadır. Modelimizde hastalık yoğunluğu her gün HES yoğunluk haritası üzerinden takip edilmektedir. İstanbul'u kapsayan harita bölümlenmiş harita dilimlerine (tile) bölünerek bölgesel ve ilçe alanları tanımlanmıştır. Bölgesel alanlar için iki farklı risk skoru oluşturulmuştur. Kırmızı risk, bölgesel olarak harita üzerindeki kırmızı ve sarı alanların yoğunluğu üzerinden hesaplanan risktir. Kombine risk, bölgesel olarak harita üzerindeki tüm renkli alanların yoğunluğu üzerinden hesaplanan risktir.

Modelimiz halka açık verinin işlenmesi sonucu bir risk skoru oluşturduğundan tam olarak gerçek durumu yansıtmayabilir. Bununla birlikte bölümlendirilmiş harita üzerinde aynı anda birden fazla ilçeye ait bölge mevcut olabilir. Bu durum ilçe risklerinin hesaplanmasına karıştırıcı faktör olarak etki edebilir. 
Modelimizin ilk çıktılarını raporlamak için tarafımızca bir ara yüz geliştirilmiştir. Bu ara yüzde İstanbul genelinin ve ilçelerinin risk skorları, skorların değişimi, çeşitli zaman aralıklarındaki ortalamaları ve çeşitli zaman aralıklarına göre değişimleri harita, tablo ve grafiklerle gösterilmektedir. Ülkemizde bu konuda bir ilk olan, İstanbul için geliştirdiğimiz HES yoğunluk haritasını baz alan risk skorlama modelimizin ilk sonuçlarını sunan ara yüzü sizin ve değerli okuyucuların erişimine sunmak isteriz. Modelimizin ara yüzüne https://www.istahed.org.tr/istahed-covid-risk-takibi/ internet adresinden ya da https://datastudio.google.com/reporting/4036ce9d-01af-4014-be89-3b62f4198d30 Google tabanlı internet adresinden ulaşılabileceğini belirtiriz.

Saygılarımızla

Destek ve teșekkür:

Model geliştirme çalışmamız İstanbul Aile Hekimliği Derneği (ISTTAHED) tarafından desteklenmektedir.

Reidin - Data Analytics şirketine sağladığı teknik destekten ötürü, Mustafa Eren Er’e ise fikir ve önerilerinden ötürü teșekkür ettiğimizi belirtiriz. 


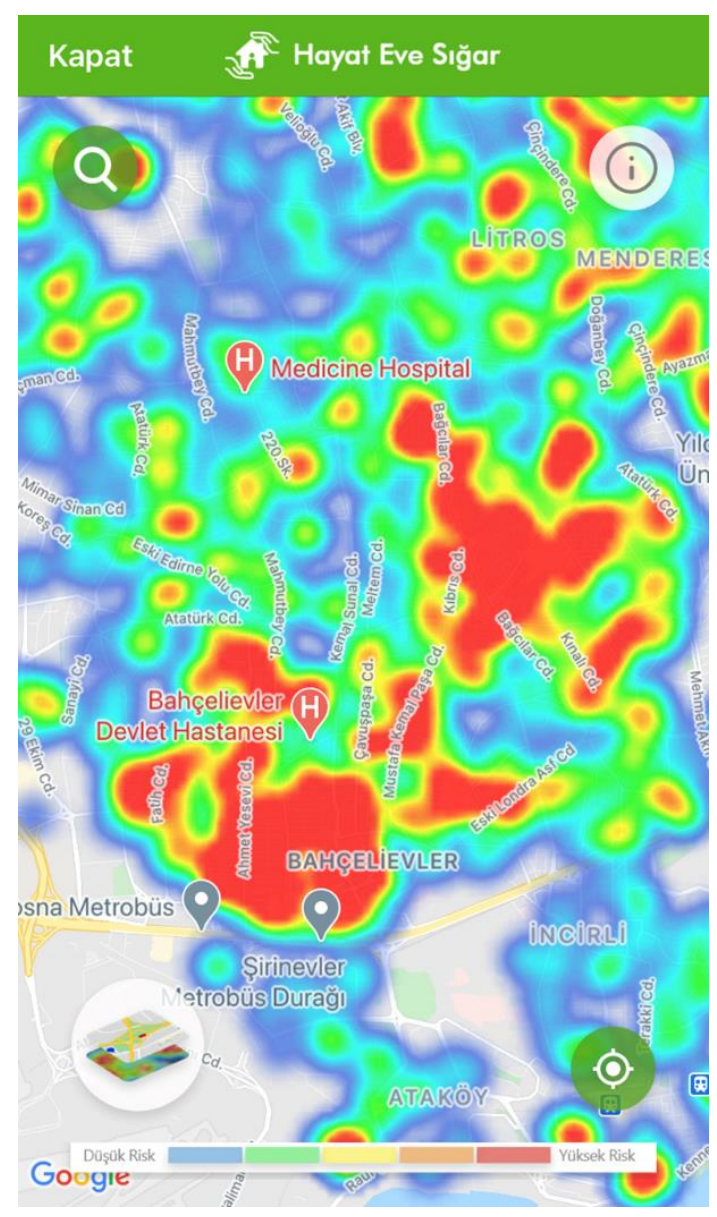

Resim 1. HES yoğunluk haritası görünümü

\section{Kaynaklar}

1. World Health Organization. WHO Coronavirus Disease (COVID-19) Dashboard.[Internet] https://covid19.who.int/ (Erişim tarihi: 21.02.2021)

2. Rafael RdMR, Neto M, Depret DG, Gil AC, Fonseca MHS, Souza-Santos R. Effect of income on the cumulative incidence of COVID-19: an ecological study. Revista Latino-Americana de Enfermagem. 2020;28.

3. Whittle RS, Diaz-Artiles A. An ecological study of socioeconomic predictors in detection of COVID-19 cases across neighborhoods in New York City. BMC medicine. 2020;18(1):1-17. 